\title{
Exploration on the New Direction of Fashion Design from the Perspective of Youth Subculture-Doll Clothing as Example
}

\author{
Shanshan Chen \\ Southwest Minzu University, Chengdu, China \\ Email: 251071809@qq.com
}

How to cite this paper: Chen, S.S. (2021) Exploration on the New Direction of Fashion Design from the Perspective of Youth Subculture-Doll Clothing as Example. Open Access Library Journal, 8: e7766.

https://doi.org/10.4236/oalib.1107766

Received: July 16, 2021

Accepted: September 12, 2021

Published: September 15, 2021

Copyright $\odot 2021$ by author(s) and Open Access Library Inc.

This work is licensed under the Creative Commons Attribution International License (CC BY 4.0).

http://creativecommons.org/licenses/by/4.0/

\begin{abstract}
Fashion design, as the name suggests, is an industry of designing fashion styles. Conventional clothing design and production take real human beings as the carrier. With the development of subculture, the words "doll circle", "doll mother" and "doll clothes" have gradually come into the daily life of more and more people, and the word "doll" here does not refer to human children, but refers to dolls such as Barbie dolls. "Doll mother" is the name of the doll-raising group, and "doll clothes" is the clothing of the dolls. 1/6 doll is the way that the size of the doll circle is marked, which is the height setting on the basis of $180 \mathrm{~cm}$, representing a doll of about $30 \mathrm{~cm}$ height. From the perspective of youth subculture, this paper analyzes the ideas, methods and difficulties from clothing design to doll clothing design, takes embroidery as inspiration, carries on the innovative design and production practice of $1 / 6$ doll clothes, and tries to explore the new direction of clothing design.
\end{abstract}

\section{Subject Areas \\ Culture, Industrial Engineering}

\section{Keywords}

Doll Clothing Design, Clothing Production, Subculture, Youth Subculture

\section{Introduction}

Compared with the mainstream culture, subculture is niche and non-mainstream. The reason for its formation can be summarized as that niche groups actively seek the style outside the mainstream and have more aggression. Subculture can be divided into youth subculture and old subculture according to age. In the 
post-war British Birmingham School vision, youth subculture refers to "emerging groups or new life styles with certain abnormal color or challenge constantly appearing in the framework of social class structure" [1]. In the all-media era, youth subculture refers to "cultural practice of youth groups expressing themselves creatively based on common interests and value pursuit" [2].

Throughout the development of youth subculture since the reform and opening, we can clearly see that the youth subculture of each era is on the basis of fully absorbing the rules and resources of the mainstream culture, and in the interaction with the mainstream culture, form its own unique style, and in turn shape and changing the mainstream culture and social structure [3]. Contemporary youth were born in the consumer society and Internet era, and their political aspirations are relatively weak, and their consumer subculture is mainly reflected in fashion culture [4]. For example, the popular "Han suit circle", "lo maiden circle", "JK uniform circle" and other circles are the embodiment of subcultures in fashion. The love of dolls is no longer exclusive to children. New professions such as "doll collector", "doll makeup artist" and "doll costume writer" have emerged in the "doll circle", among which the doll designer specializes in designing and making clothes for dolls. There are some excellent works among them. There are many ways to express a hobby, and there are interesting similarities between seemingly unrelated hobbies. For example, when people who like fashion design and traditional handicrafts collide with the doll-raising people, they are actually building the ideal world in their hearts.

There are many kinds of dolls, and there are different gender, age, size and stature settings, such as ob dolls with a head-to-body ratio of 1:1 or 1:2. Its main style is cute, height about $15 \mathrm{~cm}$, and even manufacturers or individuals launch miniature dolls, and height is only $5 \mathrm{~cm}$. There are also various sizes of BJD ball joint dolls, which are divided into $1 / 3$ doll $(60 \mathrm{~cm}), 1 / 4$ doll $(45 \mathrm{~cm})$, etc. Most of the most famous Barbie dolls are about $30 \mathrm{~cm}$ in height, and their body proportion is much taller than that of real humans, especially the leg ratio, which is similar to the standard model, which is more suitable for the display of fashion design. There are many similar doll communes in China, such as bedoll (Figure 1) and kissmela (Figure 2). These dolls have spherical joints to achieve the purpose of limb movement, so they can move freely and pose close to real people.

Under the influence of subculture, doll clothing design, as a subdivision of clothing design, gradually moves from minority to public vision, and constantly broadens the direction of clothing design with strong momentum to create new possibilities for clothing display. For example, the auction price of the small cloth doll clothing of Harusya, a well-known Japanese doll clothing designer, is no less expensive than the price of real clothes, even more expensive; another example, the Moschino 2021 Spring/Summer Milan Fashion week in 2020 adopted the form of puppets for clothing display, and there are also senior doll clothing designers in the joint circle of well-known doll houses and bedoll in China to make a show of doll and its clothes, creating new ideas for the display of clothing design. At present, the design of doll clothes is still a blue sea market, with a great 


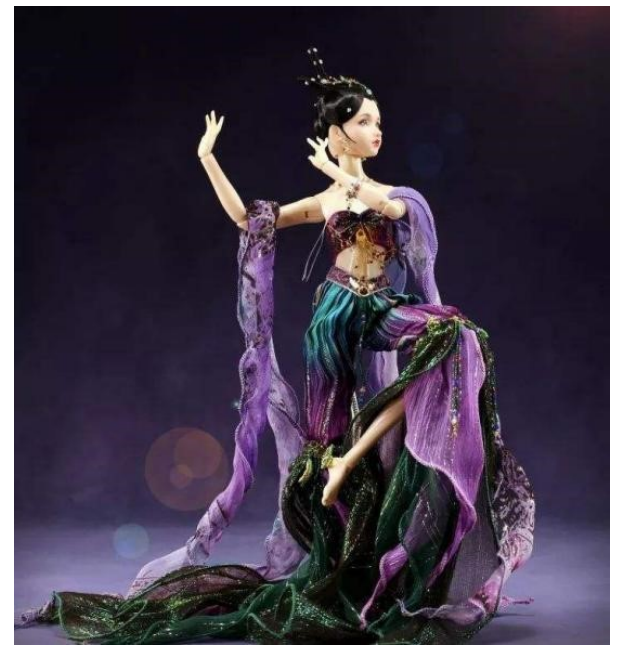

Figure 1. Bedoll (Source: Internet).

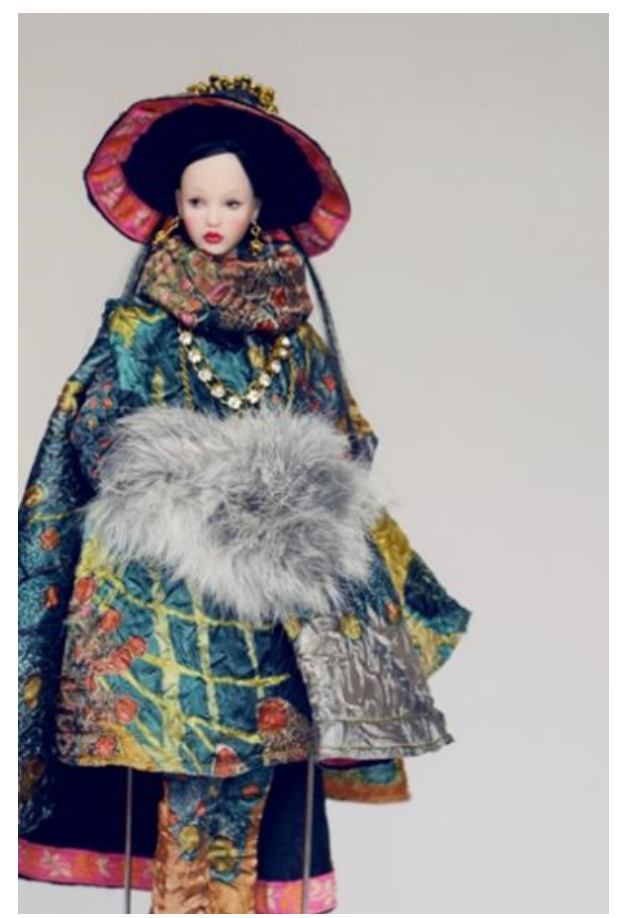

Figure 2. Kissmela (Source: Internet).

market space, and a large part of the doll mother is a group with leisure and money. Its momentum can be seen from the auction of doll and doll clothes. In addition to the doll's creators, its derivative markets include doll hairstylists, makeup artists and clothing designers in short supply, especially those in the forefront of technology often use registration-lottery-queuing or appointment system, and the waiting period is calculated by years, which shows the degree of popularity. The mainstream culture is dynamic, which makes it possible to transform some forms of youth subculture into mainstream culture [5]. The active market of doll clothes fully indicates that there are still many explorable directions for clothing design in the subcultural perspective, and there are broader 
business opportunities that deserve further research.

\section{Analysis on the Design Points of Baby Clothes}

There are two directions in the design of doll clothes in the current market, joint reproduction and innovative design.

\subsection{Joint Reproduction}

Often appears on big brand dolls, taking the well-known American doll brand Integrity Toys as an example, its series includes Fashion Royalty (short for fr), poppy Parker (short for pp), nuface, nufantasy, monogram, and so on. The joint reproductions are diverse, and clothes specially designed for them are designed by well-known designers. Take Wu Jigang, a well-known Chinese fashion designer, as an example, he graduated from Parsons School of Design, he started designing doll clothes for toy companies at the age of 16, worked as a designer for the Fashion Royalty series, and is an excellent women's wear designer, famous for designing the dress of US first Lady Michelle for his inauguration ceremony in 2009.

The methods of reproduction include the show costumes, ready-made clothes or cartoons, and the character costumes in the film according to the proportion of the dolls, and could be scaled at 1:1 in styles, colors, patterns and so on. It should be emphasized that reproduction is not equivalent to plagiarism, but that the authorities have granted copyright to cooperate. You should have the sense to know that the "doll circle" has a very strong crackdown on piracy, and the "doll mother" will spontaneously resist piracy and not only do not buy it. And once found, they will use legal to warn them and take the initiative to protect the environment in the circle. In the reproduction the faces of dolls, the shape of the face, makeup, characters and costumes are all made very similar to characters, such as the well-known fairy tale themes "Beauty and the Beast" and "Snow White"; the movie "Roman Holiday"; well-known shopping malls such as Bergdorf department stores and Coca-Cola Co., Ltd.; clothing reproduction is not only like DIOR, CHANEL general first-line brands, but also HM, Aymeline and other fast fashion brands.

Take Barbie's parent firm of Barbie's Mattel as an example. In 2019, Disney teamed up with Mattel to focus on Star Wars. Episode IV-A New Hope, the first Star Wars film released in 1977, producing three classic character dolls. As shown in Figure 3, Darth Vader Barbie, dressed in a shiny black blouse, high-waisted pencil trousers and over-the-knee boots, the cool black cape is a great addition to the aura, exquisite makeup, flaming red lips and with sunglasses, properly turning into a dark lord with a very mysterious color.

Taking Disney as an example, Disney's princess series of toys although not sold as well as Barbie, but it is not a small volume. According to the estimate of Needham analysts, annual sales of Disney princess toys are about $\$ 500$ million in 2016, accounting for about 7.5\% of Mattel's total sales last year. 


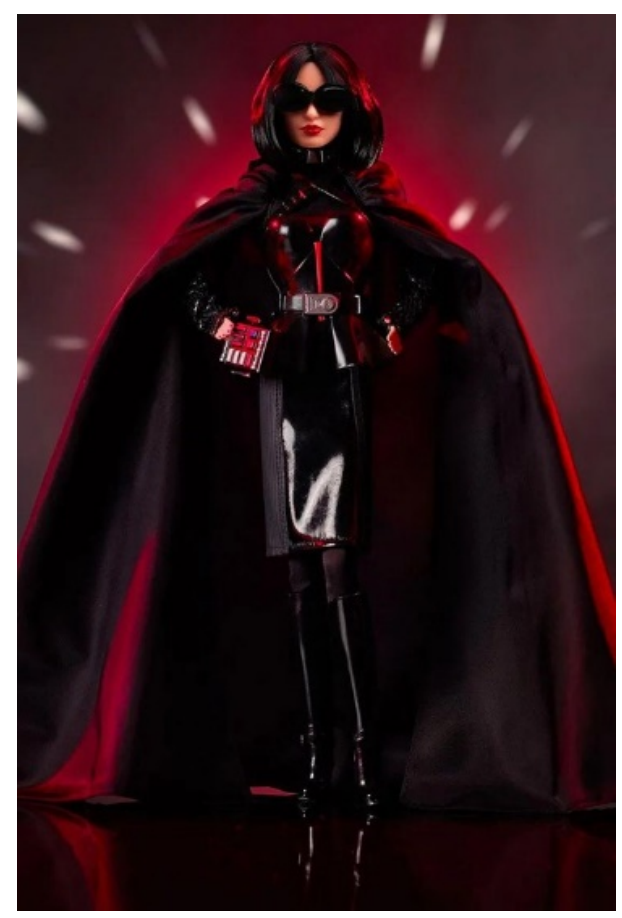

Figure 3. Darth Vader Barbie, a classic star wars character (Source: Internet).

After the release of Frozen in 2013, princesses Elsa and Anna quickly became girls' favorite toys. In 2014, a survey by the American Retail Federation showed that about $20 \%$ of parents were willing to buy the new princess toy for their daughter, surpassing Barbie to become the most popular toy for girls.

For example, Blythe doll, the Chinese doll circle affectionately calls her "Xiao Bu". It is a doll with high price, rapid appreciation and crazy in the world. It is also one of the most popular dolls in China. The price of conventional doll clothes ranges from tens to thousands of yuan (Figure 4).

The price of clothes designed specifically for Blythe by doll designers can be as high as five figures, and many of the world's top boutique brands are also interested in her, and have made her brand classic "Blythe version of custom clothing". Many independent clothing designers also specialize in the design and production of small cloth, once again for the Blythe doll to open a wider "door of change" (see Figure 5).

\subsection{Innovative Design}

Innovative design ideas are consistent with conventional clothing design, from the collection of inspiration, to design are original, the difference is that the model has been changed from a real person to a doll of different sizes.

In the design of doll clothes, because the models are not real people, in addition to the difficulties of wearing and taking off, the comfort of clothing could almost not be considered, so we can try a variety of materials, even non-wearing fabrics, and out-of-season clothing collocation can also be fully tried. There is no 


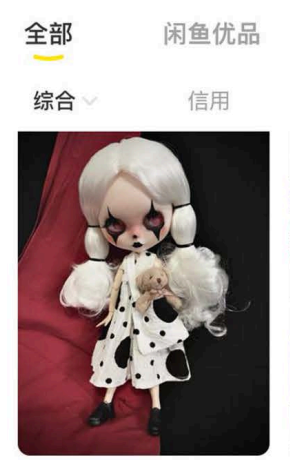

小布娃衣blythe娃衣全新 自制, 贩售中 连衣裙 +斜

$$
\text { Blythe 全新未拆封 }
$$

$$
¥ 30 \text { 1人想要 }
$$

ब的广东

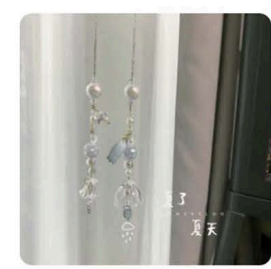

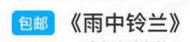

Blythe\#娃衣娃物\#小布铃

全新未拆封

$¥ 59$ 53人想要
会玩用户 全部闲鱼优品

区域

篮选 三

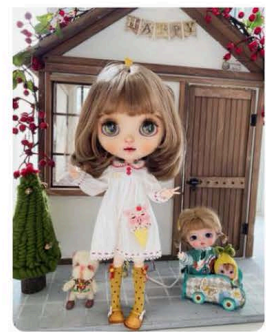

【现货可直拍】小布娃衣 Blythe娃衣套装 图1-8是 全新未振封

$¥ 89$ 144人想要

存广东口芝麻信用极好

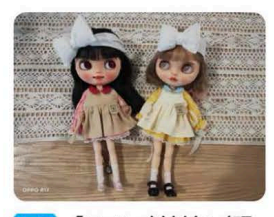

包㫼【blythe材料包 (现 货可拍）】小布娃衣材料 ¥52 92人相要

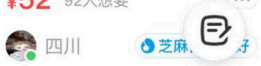

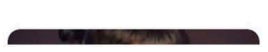

综合

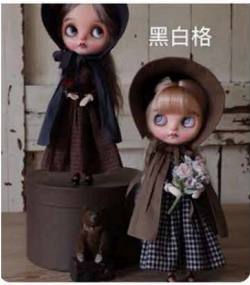

出blythe家庭教师复古娃 衣 KX简爱复古娃衣 棕红 Blythe 轻微使用痕迹 $1 / 6$ $¥ 450$ *450 2人想要

B. 江苏菠麻信用极好

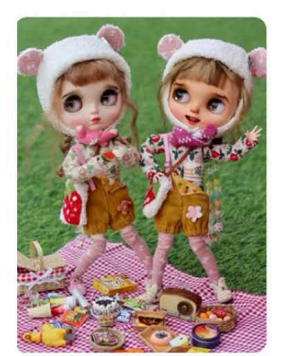

包畉《第二批》blythe小 布辣辣娃衣《第二批预 $¥ 128$ 214人相要

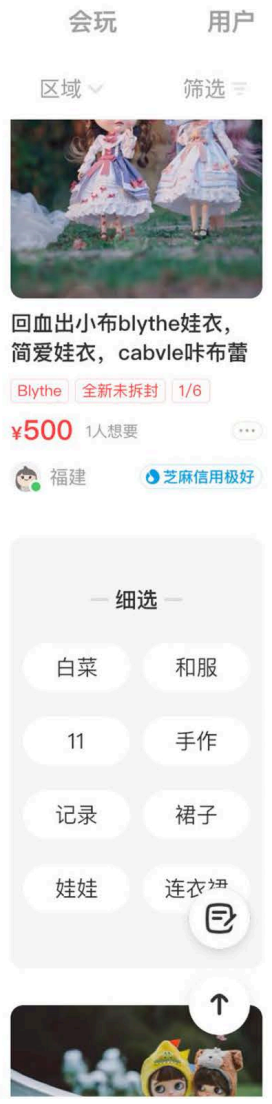

全部

综合

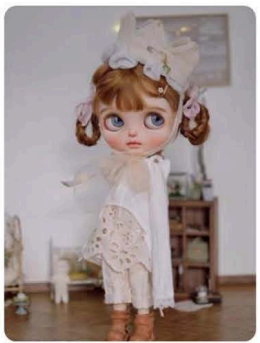

旬的出英苒同款 Blythe小 王子套装娃衣 原价1690

Blythe 全新未拆封

¥1500 2人相要

응 0 上芝麻侮用极好

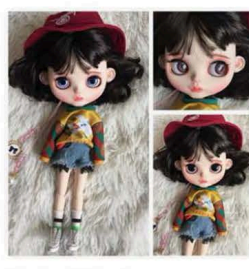

分䐓兔息 包的 Blythe小布 娃娃黑色短发19关节体白

$¥ 78.75$ 2人付敖

-
会玩用户
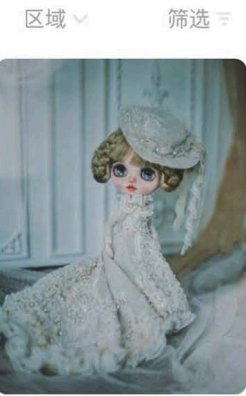

包的【刀出】秋露 SoN六 壹捌 Blythe娃衣 直出一套 全新未㧓封 全新无璒症 ¥1000 6人想要

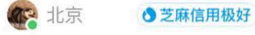

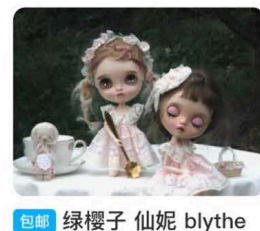
娃衣小布娃衣粉黛 无加 Blythe 全新未振封 $¥ 1080$ 16人想要

○上海芝麻信用极好

Figure 4. Blythe clothes design works (Source: Internet).

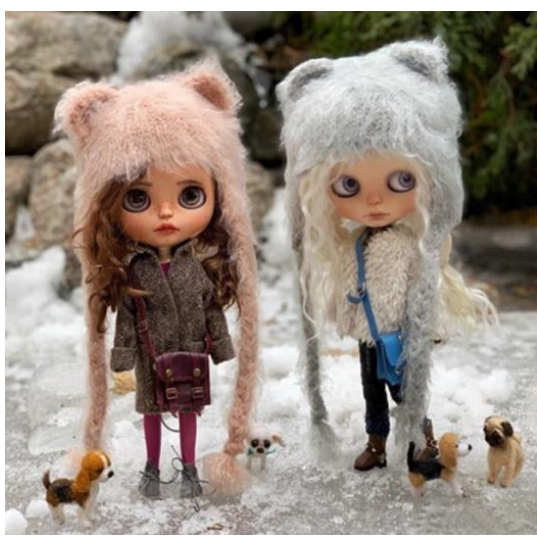

Figure 5. Blythe clothes design works (Source: Internet).

consideration for the need of clothing to be warm in winter and cool in summer, which greatly broadens the scope of clothing design.

\section{The Main Points and Methods of the Design and Production of Doll Clothes}

\subsection{Size Analysis of Doll Clothes}

The height and shape of dolls are very diverse, and their height is based on 180 
$\mathrm{cm}$, the most common kinds of children are those of $1 / 3(60 \mathrm{~cm}), 4 / 1(45 \mathrm{~cm})$, $1 / 6(30 \mathrm{~cm})$ and $1 / 12(15 \mathrm{~cm})$, but there are also some very minority dolls, such as dolls with only $5 \mathrm{~cm}$ in length, even at such a mini size, the doll has all the features, hair, fingers, and clothing, and can move, is very exquisite. The doll's figure is also very diverse, the child's body is characterized by a large head and small body, basically a three-head body or five-head body ratio, arms and legs thick and short, presents a lovely style overall; the adult body usually simulates the body shape of a model, in which the female body is divided into different chest shapes, so it is necessary to measure and analyze the designed doll model.

\subsection{The Plate-Making Method of Doll's Clothing}

The plate-making method of children's clothing is the same as that of conventional clothing, plane plate-making and three-dimensional cutting can be used to realize the design idea.

\subsubsection{Plane Plate-Making}

Plane plate-making, according to the measurement data in accordance with the formula calculation and drawing the paper pattern, cut out and put out the seam allowance can be. This kind of method is more rigorous, but difficult, and different doll body shapes are different. If you want to design and make a close-fitting style, you need to be flexible, and you need to have the learning basis of clothing design and plate-making.

\subsubsection{Three-Dimensional Cutting}

Three-dimensional cutting is different from conventional three-dimensional cutting, although doll clothes can also be operated on the platform of special people, but because the size is too small, it is impossible to strictly complete the steps of three-dimensional cutting. This should have some steps in testing and omitting. The simple way is to use cling film to tightly wrap the doll body tightly, draw the needed profile directly with a pen, and then cut off the rubbing plate, pay attention to the need to trim the three-dimensional place and draw the dart. The darts of doll clothes are usually cut in the form of cutting to reduce the thickness of the seams.

\subsection{Analysis of Difficulties and Solutions in the Production of Doll Clothing}

Analysis of difficulties and solutions in the production of doll clothing the biggest difference between doll clothing design and conventional clothing design is that doll clothing is a miniature model that has shrunk tens of times, and many conventional processes and details in clothing production are difficult to achieve. Taking sewing as an example, for example, the shoulder width of some doll clothes is only $2.8 \mathrm{~cm}$. In the process of sewing, if it is not a skilled worker, the industrial high-speed flat sewing machine is more difficult to grasp such a short sewing distance, and when the sewing parts and clothing pieces are too small, it 
is also easy to be sandwiched in the middle of the cloth feeding teeth in the sewing process, resulting in irreversible fabric damage, so the doll clothing is mostly made by portable sewing machines, and the sewing speed is slow. The fabric is not easily clamped.

Then taking the treatment of seams as an example, the seams of conventional inexpensive clothing are often processed by edge-cutting machines, and the stitches of most conventional three-thread edge-locking machines are about $0.5 \mathrm{~cm}$ wide, while the seams of doll clothes are mostly $0.2 \mathrm{~cm}$, which is obviously not suitable for the sewing treatment of children's clothes. The stitches of the secret copying machine are narrow and the width can be satisfied, but the seams after close cuffing will become very thick. Higher-end clothing will use rolling strips to wrap rough edges, which is about $0.6 \mathrm{~cm}$, and it is not suitable for sewing of doll clothes. Therefore, in the sewing treatment of doll clothing, the more exquisite and high-priced doll clothes can be used to sew to complete the purpose of hiding rough edges, and some of the more inexpensive ones use narrow $\mathrm{z}$-shaped stitches to deal with the edges of the seams, but the effect of anti-detachment is not as good as that of three-thread trimming, and children's clothes directly choose fabrics that will not break off when choosing fabrics, and the cheaper ones use edge-locking liquid once and for all, so that the edges will not break off. But the disadvantage is that the rough edges will harden.

Taking the choice of fabric as an example, the fabric of doll clothing is too thin, coupled with its small piece of clothing, easy to clip in the machine, and easy to tear in the process of flipping, and if it is too thick, it is difficult to turn from the negative side to the front, especially the narrow sleeve part. Therefore, while ensuring the effect, we need to consider the production factors for adjustment. The sewing technique of double-sided tweed is suitable for making doll clothes, because it has two layers, and sewing can hide the seams after peeling off. Both sides are very beautiful, so they are loved and chosen by most doll clothing designers; the technique of making leather bags is also used to make doll clothes, and the leather or imitation leather fabrics are not separated, so they also have great advantages, and the doll clothes made by these two methods are more exquisite and expensive. In the production of doll clothing, the flexibility and convenience of crochet and knitting are very suitable for the production of doll clothing.

\section{The Innovative Design and Practice of the Doll Clothes This Time}

The doll clothes created this time take 1/6 baby of the brand Kissmela as the model. The design method is innovative design, it is proposed to present the natural handmade doll clothes style, combining the traditional handicraft-embroidery, Dazi embroidery and blue dyeing process to get the unique fabric after recreation, making it more in line with the design style and with a warm rustic feeling. Specific measurement dimensions are shown in Table 1. 
Table 1. Product dimensions (unit: $\mathrm{cm}$ ).

\begin{tabular}{cccccccc}
\hline Part & $\begin{array}{c}\text { Dress } \\
\text { length }\end{array}$ & Bust & $\begin{array}{c}\text { Shoulder } \\
\text { width }\end{array}$ & Waist & $\begin{array}{c}\text { Sleeve } \\
\text { length }\end{array}$ & $\begin{array}{c}\text { Sleeve } \\
\text { width }\end{array}$ & $\begin{array}{c}\text { Back } \\
\text { length }\end{array}$ \\
\hline size & 24.5 & 13 & 4.5 & 13 & 7 & 3 & 6.5 \\
\hline
\end{tabular}

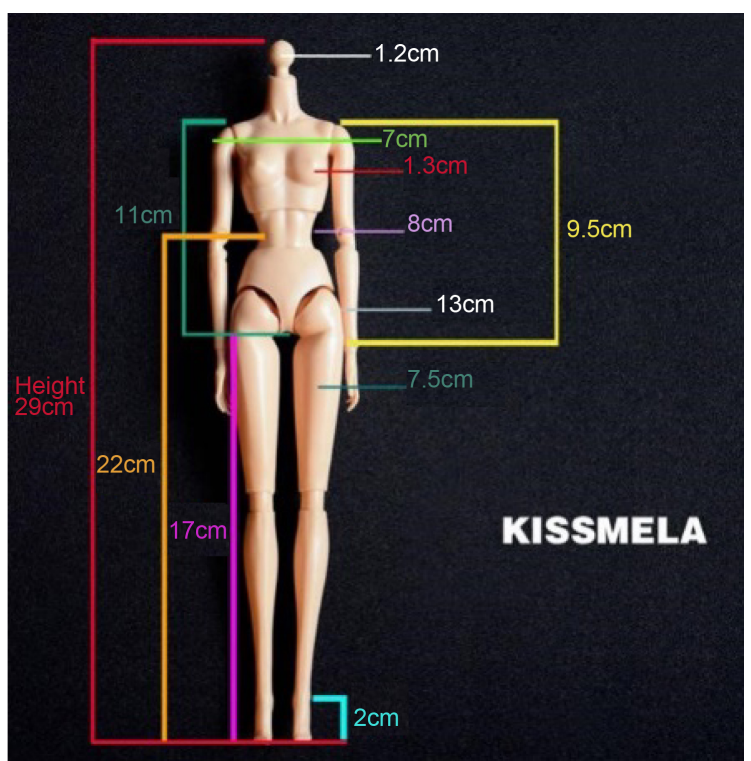

Product name: KISSMELA 1.0

Material: PVC

Height: $29 \mathrm{~cm}$

Head joint: flexible

Joints: 17, flexible

Color: pinkish white skin, pinkish popular skin

Note: hands and legs cannot be removed or replaced

(Kissmela body size display)

Doll clothing design inspiration from traditional Japanese handicraft-embroidery (see Figure 6), early embroidery is mainly used for clothing thickening and mending, derived from people's demand for warmth and saving, the integration of rural style and complex design, with the development of social and economic level, the use gradually changed from practical to decoration, to modern times Embroidery has developed into a pure decorative embroidery art. Embroidery literally means "small thorn", which is an accurate description of the simple flat stitch used in this traditional technique [4]. In terms of fabric selection, the use of Banlangen manual blue-dyed pure cotton fabric, with natural characteristics, a special plant flavor, thickness and yarn density are suitable for the use of embroidery techniques, and can present the expected natural handmade doll clothing design style.

When the doll clothes using a dress style, the back to do a concealed button closure design, easy to put on and take off. Embroidery is carried out after the doll clothes are sewn to the upper and lower body splicing-front and rear shoulder stitching-armholes and clothing pieces are stitched together. In this way, the position of embroidery can be grasped more accurately, and the size and density of embroidery can be flexibly adjusted according to the actual effect. The process is shown in Figure 7. This time, the Japanese Chuangnei embroidery classic rice flower stitch method and Chinese traditional seed embroidery needle method are used to form diversified and rich visual effects (see Figure 8). 


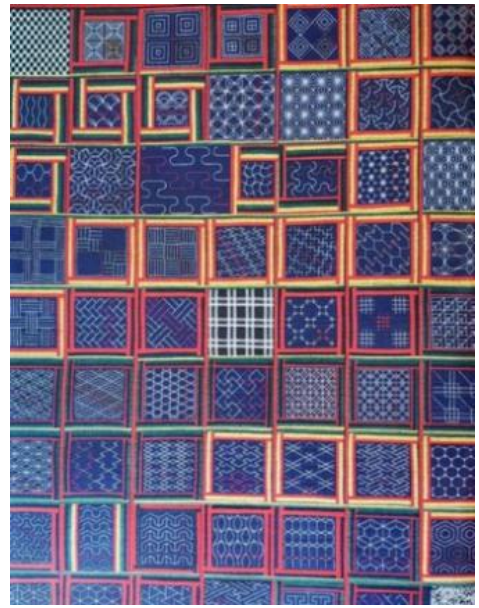

Figure 6. Embroidery part of the stitch (Source: Photo by author).

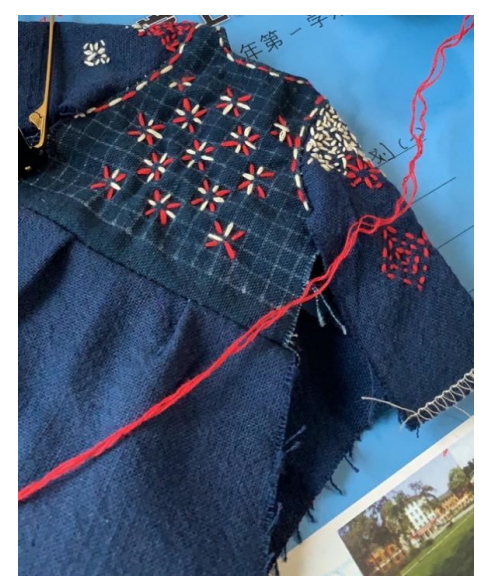

Figure 7. The process of embroidery (Source: Photo by author).

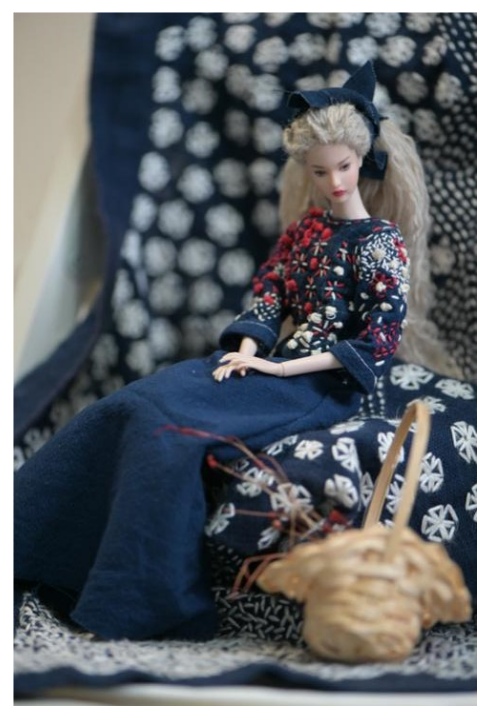

Figure 8. Finished doll clothes (Source: Photo by author). 


\section{Conclusions}

China's 14th Five-Year Plan suggests that the rise of new consumption is unstoppable in the future, including customized consumption, experience consumption and fashion consumption, and "baby clothes" belongs to the typical new consumption category. In the post-consumerism era, subcultures are flourishing and blossoming, and the tolerance of audiences is being broadened. The mutual transformation of subcultures and mainstream culture means the future direction and business opportunities, and clothing design under the subculture perspective has great potential for development.

Most of the doll clothing designers operate in the form of independent studios, and the clothing is mostly hand-made or customized, and the output is low, which is one of the reasons for its high price. A very small number of designers and clothing companies began to test the doll clothes and real clothes like operation, assembly line production, brand building and publicity, opening up a new direction of clothing design, and it is also a promising road of industrialization.

This paper selects diversified cases to analyze the style, design techniques and market demand of baby clothes, summarizes the development trend of doll clothes, and composes and practices the design process of doll clothes under the subculture perspective from both design and production levels, pointing out a new development direction for the segmentation of clothing design. Due to the length of the article, this paper only analyzes a practical case with certain limitations, and there is more space to be explored in design style and production methods, which is intended to be further expanded in the subsequent research.

\section{Funding}

This thesis is a project supported by the Fundamental Research Funds for the Central Universities, Southwest Minzu University (project number 2016SZYQN58).

\section{Conflicts of Interest}

The author declares no conflicts of interest.

\section{References}

[1] Hall, S. and Jefferson, T. (2015) Resistance through Ritual, Youth Subculture in Post-War Britain. Translated by Meng, D.Y., Hu, J.F. and Wang, H., China Youth Publishing House, Beijing.

[2] Ping, Z.Q. and Wei, X.R. (2018) Social Conflicts, Communication and Governance of Online Youth Subculture. China Youth Studies, 11, 35-41.

[3] Yan, C.J. (2019) Historical Evolution of Youth Subculture in China. Chinese Youth Social Sciences, 38, 83-91.

[4] Jiang, W.N. (2018) Interpretation of "Two-Dimensional" Consumption Subculture of Post-90s College Students. Journal of Guangxi Normal University Philosophy and Social Sciences Edition, 54, No. 1, 70-75. 
[5] Cui, J.X. (2018) An Analysis of the Concept of Youth subculture-A developmental Investigation Based on the Historical Evolution of Youth Subculture. Study and Practice, No. 11, 134-140. 